Revista de Iniciação Científica em Odontologia. 2018;16(3):137-143

ISSN 1677-3527 - DOI: 10.4034/RevICO.2018.16.3.14

Relato de Caso

\title{
Remoção de sialoadenite crônica: relato de caso clínico
}

\author{
Chronic sialoadenitis removal: clinical case report
}

\begin{abstract}
Jannerson Cesar Xavier de Pontes ${ }^{1}$; Ilky Pollansky Silva e Farias ${ }^{2}$;
Cassiano Francisco Weege Nonaka ${ }^{3}$; Yuri Wanderley Cavalcanti ${ }^{4}$.
\end{abstract}

${ }^{1}$ Graduando em Odontologia pela Universidade Federal da Paraíba, João Pessoa, Paraíba, Brasil. ${ }^{2}$ Mestrando do Programa de Pós-graduação em Odontologia da Universidade Federal da Paraíba, João Pessoa, Paraíba, Brasil.

${ }^{3}$ Professor do curso de Odontologia, Universidade Estadual da Paraíba, Campina Grande, Paraíba, Brasil.

${ }^{4}$ Professor do curso de Odontologia, Universidade Federal da Paraíba, João Pessoa, Paraíba, Brasil.

Autor e endereço para correspondência:

Yuri Wanderley Cavalcanti - Universidade Federal da Paraíba, Centro de Ciências da Saúde Campus I, Departamento de Clínica e Odontologia Social. João Pessoa, PB - Brasil - CEP: 58051900. Email: yuri@ccs.com

\begin{abstract}
Resumo
Introdução: A sialoadenite é um processo inflamatório das glândulas salivares, podendo ser infeccioso ou não. Quando infeccioso, pode ser de origem viral ou bacteriana. Sua prevalência é $0,1 \%$ na população e não há predileção por sexo ou faixa etária. Relato de caso: O objetivo deste texto é relatar o procedimento cirúrgico de biópsia excisional de uma lesão por extravasamento de muco associada à sialoadenite crônica. Conclusão: A sialoadenite apresentada neste estudo assemelhase às mucoceles orais, que tem maior prevalência em lábio inferior. A conduta clínica para a remoção da lesão foi a mesma das mucoceles, a qual apresentou um bom resultado pós cirúrgico. O diagnóstico precoce desse tipo de lesão é importante para a devolução do bem estar do paciente e remoção completa da patologia de maneira pouco invasiva.
\end{abstract}

Descritores: Sialadenite. Cirurgia. Patologia. 


\begin{abstract}
Introduction: Sialoadenitis is an inflammatory process of the salivary glands, and may be infectious or not. When infectious, it may be of viral or bacterial origin. Its prevalence is $0.1 \%$ in the population and there is no predilection for sex or age group. Case report: The objective of this text is to report the surgical procedure of excisional biopsy of a lesion due to extravasation of mucus associated with chronic sialoadenitis. Conclusion: The sialoadenitis presented in this study resembles oral mucoceles, which has a higher prevalence in the lower lip. The clinical conduct for removal of the lesion was the same as for the mucoceles, which presented a good postoperative result. The early diagnosis of this type of lesion is important to recover patient's well being and complete removal of the disease in a non-invasive way.
\end{abstract}

Keywords: Sialadenitis. Surgery. Pathology.

\title{
Introdução
}

Sialoadenite é um processo inflamatório das glândulas salivares, infeccioso ou não. Pode ser oriundo de infecção viral (mais comum é a caxumba) ou infecção bacteriana (mais comum é por Staphylococcus aureus) que é caracterizada por drenar material purulento. As causas não infecciosas podem ser pela síndrome de Sjögren, sarcoidose ou radioterapia e podem apresentarse na forma aguda ou crônica ${ }^{1}$.

Um estudo da Pontifícia Universidade Católica do Paraná (PUCPR) mostrou que dentre 1.990 laudos avaliados no período de 1999-2008, a prevalência de Sialoadenite foi 0,1\% e, dentre os casos, não foi observado predileção por sexo ou faixa etária².

Essa patologia é geralmente sintomática, apresentando aumento de volume e retenção de saliva na região da glândula acometida. Podem ser incluídos em seu diagnóstico diferencial: hipertrofia glandular decorrente de infecção por vírus HIV, fibrose cística, diabetes mellitus, sarcoidose e sialolitíase ${ }^{3}$.

As características histopatológicas variam entre os casos agudos e crônicos. Em lesões agudas observa-se presença de neutrófilos nos sistemas ductal e acinar. Em lesões crônicas 
estão presentes infiltrados linfoplasmocitátrios de forma difusa ou focal no parênquima glandular, sendo comum atrofia acinar e dilatação ductal. Quando se observa fibrose associada, este quadro é chamado de crônico esclerosante. O tratamento é de acordo com a característica da patologia, aguda ou crônica, mas incialmente é indicado o uso de antibióticos, analgésicos, sialogogos e massagem glandular. A intervenção cirúrgica é indicada em casos que não responderam à terapêutica medicamentosa ${ }^{1}$.

Deste modo, o objetivo deste texto é relatar o procedimento cirúrgico de biópsia excisional de uma lesão por extravasamento de muco associada à sialoadenite crônica.

\section{Relato de Caso}

Paciente do sexo feminino, 32 anos, feoderma, compareceu ao Centro Odontológico de Cruz das Armas (COCA) queixando-se de aumento de volume assintomático na região direita do lábio inferior, "caroço no lábio". A paciente não soube informar há quanto tempo a lesão surgiu, assim como sua história médica não foi contributiva e não foram observadas linfadenopatias regionais. Ao exame físico intraoral, observou-se um nódulo submucoso na região direita do lábio inferior, com aproximadamente $2 \mathrm{~cm}$ de diâmetro, recoberto por mucosa íntegra, de superfície lisa e sem alterações apreciáveis em sua coloração (Figura 1). A lesão se apresentava móvel e com consistência relativamente firme à palpação. Com base nas hipóteses diagnósticas de neoplasia glandular salivar ou neoplasia mesenquimal, foi proposta a realização de biópsia excisional.

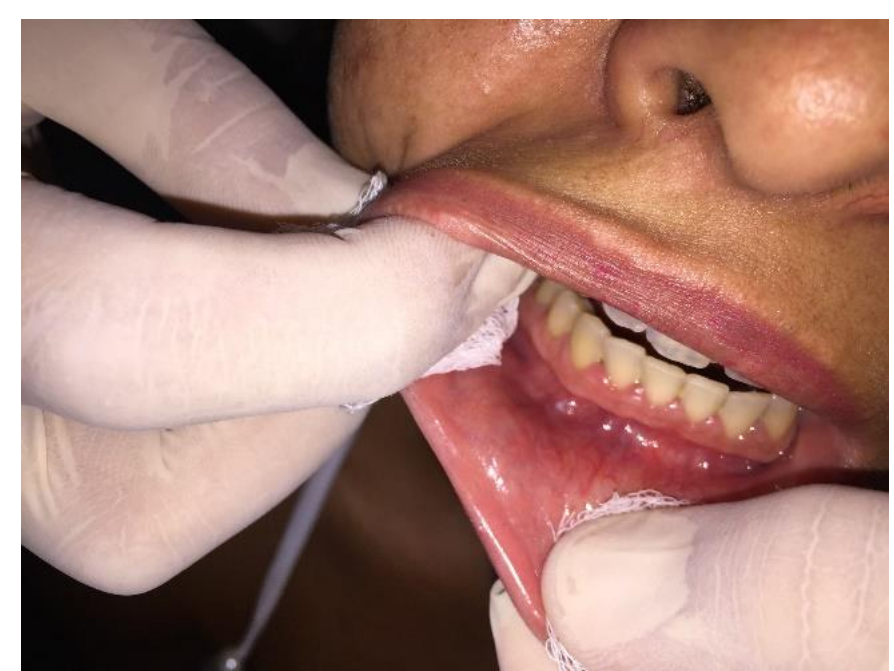

Figura 1. Região de lábio inferior apresentando, do lado direito da paciente, nódulo submucoso. 
Durante o procedimento cirúrgico, após incisão da mucosa de revestimento e divulsão dos tecidos circunvizinhos, constatou-se que a lesão exibia aspecto translúcido e arranjo discretamente lobular (Figura 2).

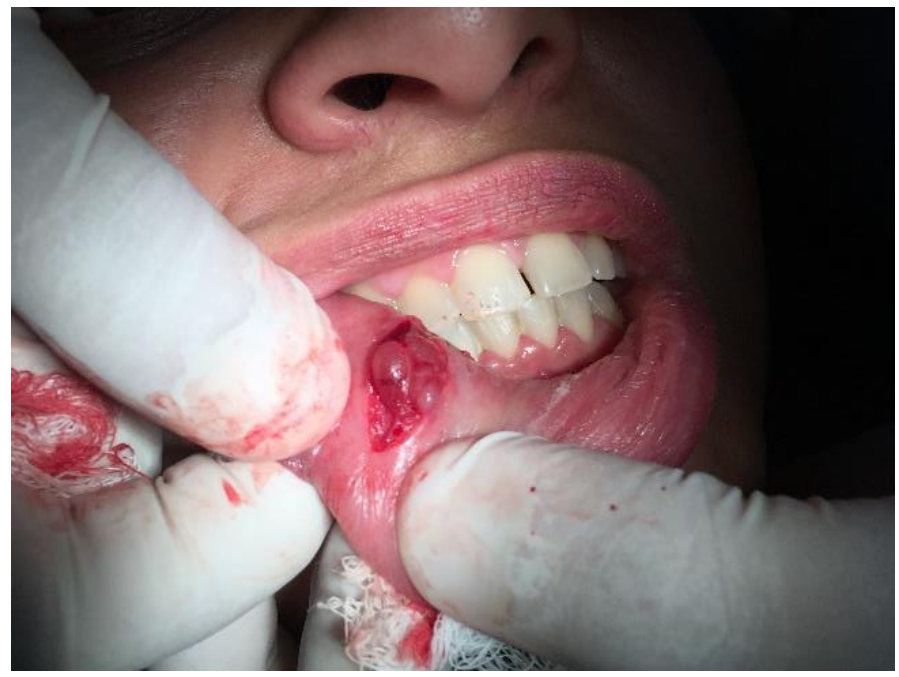

Figura 2. Aspecto clínico da lesão.

Em virtude de sua nítida delimitação em relação aos tecidos adjacentes, a lesão foi facilmente removida. Em sequência, procedeu-se à síntese com sutura oclusiva dos bordos da incisão (Figura 3) e realizou-se prescrição de analgésico (paracetamol, 750mg, 6h/ 6h, durante 2 dias) e anti-inflamatório (nimesulida, 100mg, 12h/12h, durante 2 dias).

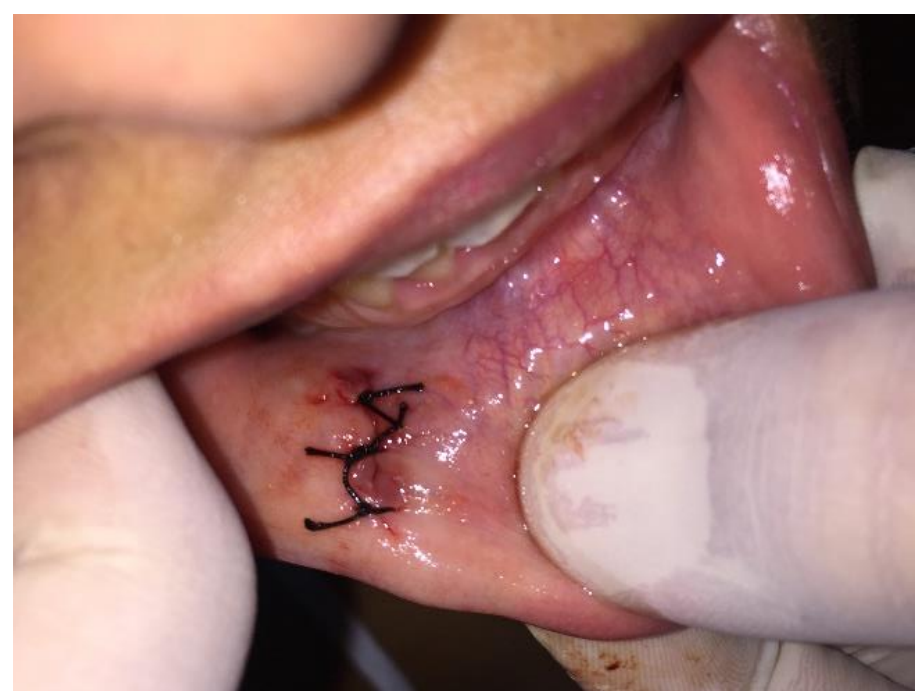

Figura 3. Aspecto clínico ao final do procedimento de biópsia excisional.

O espécime cirúrgico foi fixado em formol a $10 \%$ e encaminhado para exame histopatológico. A análise, sob microscopia de luz, revelou espaço cavitário preenchido 
parcialmente por material amorfo levemente basofílico, compatível com muco, delimitado por reação de granulação constituída por fibroblastos e vasos sanguíneos neoformados (Figura 4), permeados por infiltrado inflamatório predominantemente mononuclear, de intensidade variável.

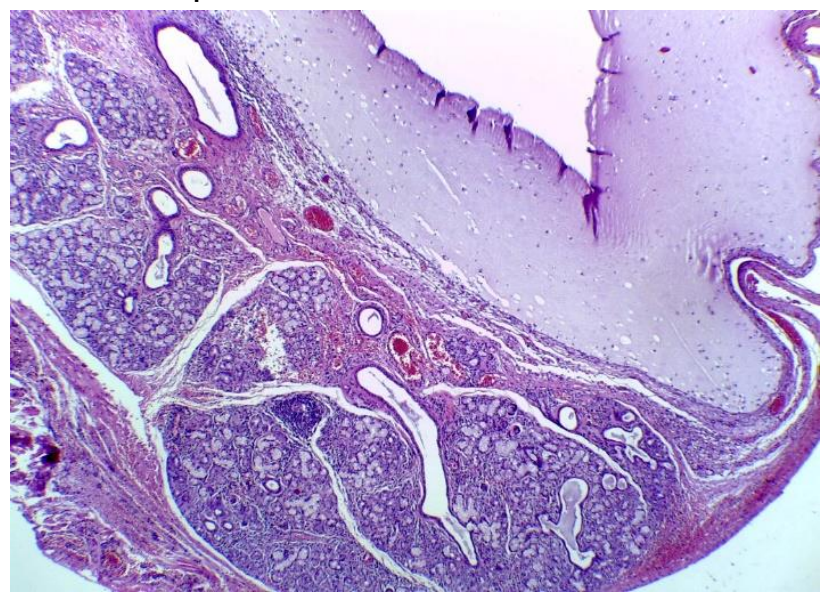

Figura 4. Fotomicrografia revelando amplo espaço cavitário preenchido parcialmente por material amorfo compatível com muco, delimitado por discreta reação de granulação, além de parênquima glandular salivar (Hematoxilina e eosina, x40).

Destacava-se, ainda, a presença de parênquima glandular salivar mucoso permeado por infiltrado linfoplasmocitário de intensidade variável e exibindo áreas de atrofia acinar, ectasia ductal e discreta fibrose (Figura 5). O diagnóstico definitivo foi de fenômeno de extravasamento de muco associado à sialoadenite crônica.

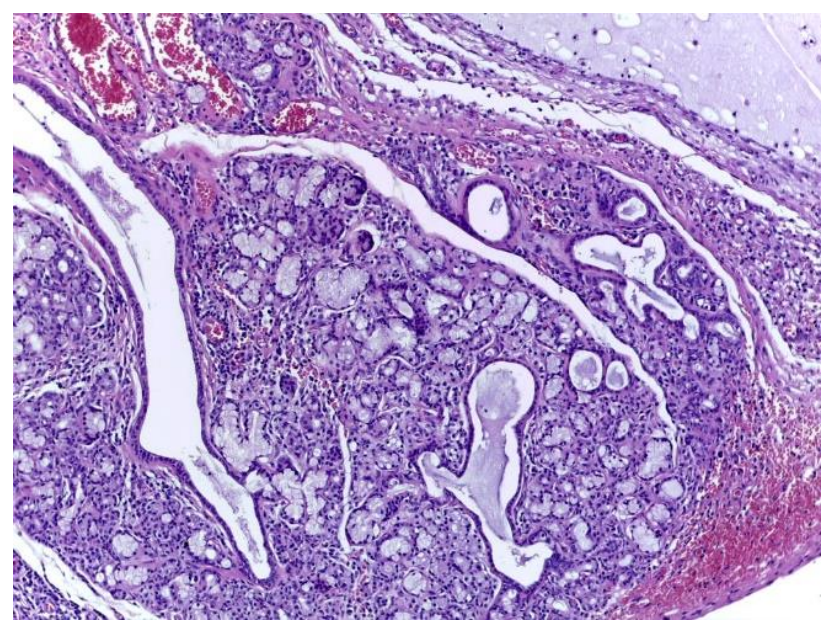

Figura 5. Destaque para as áreas de atrofia acinar e ectasia ductal no parênquima glandular salivar mucoso permeado por infiltrado linfoplasmocitário (Hematoxilina e eosina, x200). 
A biópsia excisional, neste caso, serviu como forma de tratamento devido ao tamanho da lesão e suspeita de neoplasia glandular salivar. A paciente retornou para remoção da sutura após 7 dias, apresentando boa cicatrização.

\section{Discussão}

A literatura não apresenta casos relevantes de sialoadenite similares ao exposto neste relato. A lesão que mais se assemelhou a este tipo de apresentação patológica foi a mucocele oral que é caracterizada como uma cavidade cheia de muco, sua etiologia está associada a traumas e frequentemente se apresenta na região de lábio inferior lateralmente à linha média. Embora a história médica da paciente não tenha detalhado aspectos importantes como a presença de trauma antes do surgimento da lesão, o caso corrobora com os achados da literatura que apresentam-se em lábio inferior e lateral à linha média4-6.

O surgimento dessas lesões foi enunciado como comum2 e sua prevalência foi descrita em alguns estudos 5,04\% 7 e 2,9\%2. O sexo feminino foi indicado como o mais acometido e confirma a condição da paciente deste relato, que é do sexo feminino2.

A conduta clínica para o tratamento de excisão cirúrgica concorda com as atuações adotadas frequentemente, e indicadas em casos de mucocele. O histopatológico junto aos achados clínicos confirma a hipótese diagnóstica do cirurgião-dentista3-6.

A recidiva não é comum para este tipo de lesão4. No presente caso a paciente não manifestou eventos de recidiva da lesão. Embora casos como este sejam pouco frequentes, eles tem complexidade baixa e não demandam de grandes esforços para que a conduta seja resolutiva no âmbito ambulatorial da saúde pública. Em seu dia-a-dia, cirurgiões-dentistas podem encontrar casos como este e o procedimento pode ser realizado de forma rápida, porém cuidadosa, por meio de excisão cirúrgica.

\section{Conclusão}

A sialoadenite apresentada neste estudo assemelha-se às mucoceles orais, que tem maior prevalência em lábio inferior. A excisão cirúrgica é indicada em mucoceles e foi preconizada no presente caso, a qual apresentou um bom resultado pós cirúrgico. O diagnóstico precoce desse tipo de lesão é importante para a devolução do bem estar do paciente e remoção completa da patologia de maneira pouco invasiva. 


\section{Referências}

1. Neville BW, et al. Patologia Oral \& Maxilofacial. 3르 ed. Rio de Janeiro: Elsevier; 2009.

2. Bettio A, et al. Prevalência das lesões de glândulas salivares em laudos histopatológicos do Laboratório de Patologia Experimental da PUCPR no período de 1999-2008. Revista SulBrasileira de Odontologia. 2009; 6(3):231-236.

3. Gomes RT, et al. Sialoadenites: revisão de literatura sobre a etiologia, o diagnóstico e o tratamento. Arquivos em Odontologia. 2006; 42(4):288-296.

4. Freitas MCA, et. al. Terapêutica interdisciplinar na mucocele oral: relato de caso. Revista UNINGÁ. 2012; 31(1):105-112.

5. Poulopoulos A, et. al. Salivary Mucoceles in Children and Adolescents: A Clinicopathological Study. Global Journal of Medical and Clinical Case Reports. 2017; 1(4): 11-14.

6. Thukral H, et. al. Oral Mucocele: A Case Report. World Journal of Pharmacy and Pharmaceutical Sciences. 2017; 6(11): 1259-1264.

7. Bertoja IC, et. al. Prevalência de lesões bucais diagnosticadas pelo Laboratório de Histopatologia do UnicenP. Revista Sul-Brasileira de Odontologia. 2007; 4(2): 41-46. 